\title{
Apontamentos para uma reflexão sobre a função social das tecnologias no processo educativo
}

Liliana M. Passerino

Universidade Federal do Rio Grande do sul

\section{Resumo}

De forma direta ou indireta a tecnologia está adentrando nos espaços educativos. Essa ampliação tem fomentado o desenvolvimento de pesquisas no âmbito do uso das TIC na educação que tentam evidenciar os benefícios do uso dessas tecnologias na escola. Porém, a complexidade do processo de aprendizagem humano aliado à diversidade das instituições sociais e as formas de organização e práticas culturais que emergem no processo de inserção das TIC apresentam resultados inconclusivos em termos de "eficiência" escolar. Apresentamos neste artigo algumas pesquisas que mostram a relação de tecnologias e desenvolvimento apontando principalmente para as diferentes funções sociais das TIC na educação. Nosso objetivo é compreender o entrelaçamento existente entre tecnologia e processo educativo, partindo da premissa inicial que as tecnologias são instrumentos de pensamentos que inserem-se no processo educativo em função de suas características, funcionalidades e das práticas culturais que enquanto grupo social desenvolvemos com elas.

Palavras-Chave:tecnologia, função social, processo educativo

\section{Introdução}

Hoje em dia já ninguém se questiona se a tecnologia digital deveria estar presente na educação ou não, pois, a tecnologia digital, em especial, as Tecnologias de Informação e Comunicação(TIC), encontram-se fortemente disseminadas no nosso cotidiano de tal forma que podemos afirmar que existe um entrelaçamento entre tecnologias e pessoas que se concretiza nas ações que juntos desenvolvem. O presente estudo teórico parte de uma concepção que compartilhamos com Warschauer (2003) que não existe uma tecnologia "externa" introduzida para dentro visando provocar consequiências numa sociedade ou nos seus sujeitos, "ao contrário, a tecnologia encontra-se entrelaçada de maneira 
complexa nos sistemas e processos sociais" (p.23).

Pesquisas apontam para um aumento significativo do acesso à tecnologia de informação e comunicação na nossa sociedade (CGI, 2009; GALPERIN, MARISCAL,2004, GALPERIN, 2009, WAISELFISZ, 2007). Em termos de inclusão digital, de 2000 até dezembro de 2009, o acesso dos usuários brasileiros à Internet, cresceu vertiginosamente de 5 milhões para 72 milhões segundo dados da Internet World Statistics ${ }^{1}$ o que representa 36,2\% da população

Pouco a pouco de forma direta ou indireta a tecnologia está adentrando nos espaços educativos. Seja pela instalação de computadores nas escolas ${ }^{2}$, seja pelos computadores disponíveis nos domicílios ${ }^{3}$.

Essa ampliação tem fomentado o desenvolvimento de pesquisas no âmbito do uso das TIC na educação que tentam evidenciar os benefícios do uso dessas tecnologias na escola. Porém a complexidade do processo de aprendizagem humano aliado à diversidade das instituições sociais e as formas de organização e práticas culturais que emergem no processo de inserção das TIC apresentam resultados inconclusivos em termos de "eficiência" das TIC na aprendizagem escolar. Entre as pesquisas mais destacadas, encontramos a desenvolvida por Balanskat e Blamire (2007) que apresenta evidências de impacto positivo do uso das TIC na

1 Internet World Statistics- disponível em http://www.internetworldstats.com/sa/br.htm apresenta dados relativos a dezembro de 2009 .

2 o governo brasileiro tem promovido nos últimos 15 anos uma política de integração das TIC na educação básica, por meio de diversos programas, seja de formação, seja de infraestrutura. O mais antigo programa com essas características é o ProInfo, criado em abril de 1997, para promover o uso pedagógico da informática na rede pública de ensino fundamental e médio. O programa é responsável pela doação e instalação de computadores nas escolas públicas de educação básica, e a criação dos s NTE (núcleos de tecnologia educacional) que em 2009 perfazem 450 no País. Os núcleos contam com equipe interdisciplinar de professores e técnicos qualificados para oferecer formação contínua aos professores e assessorar escolas da rede pública no uso pedagógico da tecnologia e na área técnica. http://portal.mec.gov.br/index.php?option=com content\&view=article\&id=7590\&ca $\underline{t i d=210}$

3 Dados da Pesquisa de TIC nos domicílios de 2009 apontou para um crescimento significativo no percentual de acessos à Internet nos domicílios em comparação aos centros públicos pagos (lanhouse). Segundo a pesquisa, pela primeira vez desde 2007 . acesso residencial, ficou à frente das lanhouses. Tanto a posse de computador se incrementou (de 28\% em 2008 para 36\% dos domicílios com computador em 2009) como o acesso a internet passando de $20 \%$ dos domicílios com acesso à Internet em 2008, para 27\% em 2009, representando um crescimento de 35\% no período. (http://www.cetic.br/usuarios/tic/2009/analises.htm ) 
educação, especialmente no ensino de línguas e em menor medida em Ciências. Com relação à Matemática, a pesquisa mostra que existe uma aparente relação entre o tempo de uso das TIC e o desempenho escolar em testes de matemática. Outro aspecto identificado no estudo é que escolas com melhores recursos de TIC atingem melhores resultados principalmente em termos de letramento digital e que acesso a Internet de banda larga resulta numa melhora significativa nos testes nacionais de desempenho estudantil.

Outra pesquisa internacional PISA (Programa Internacional de Avaliação de Alunos), do qual o Brasil participa ${ }^{4}$ desenvolvido e coordenado pela Organização para Cooperação e Desenvolvimento Econômico (OCDE), em nível internacional e pelo INEP em nível nacional são realizadas provas e questionários a cada três anos. O PISA envolve três áreas: Leitura, Matemática e Ciências. O estudo de 2006 apresentou ainda três perguntas relacionadas com o uso de tecnologia para $\circ$ aluno $^{5}$ e um questionário para cada escola que visava identificar a situação tecnológica da mesma ${ }^{6}$. Além desses instrumentos, um questionário específico sobre TIC com perguntas sobre o uso de computadores e da internet nas escolas foi aplicado de forma opcional ${ }^{7}$. O que foi percebido no último PISA disponível é que, dos 32 países participantes e que responderam o questionário de TIC, não há evidência que o número de computadores por aluno incida no desempenho dos alunos nas provas. (PISA, 2006)

Finalmente, no estudo realizado por Balanskat e Blamire (2007) evidencia-se que a grande maioria dos professores (86\%) acredita que seus estudantes são mais motivados e atentos quando se utilizam computadores e internet na sala de aula, mas na sua maioria, os professores fazem um uso tradicional, ou seja,

4 o estudo de PISA/OCDE 2003 mostra que no Brasil a média de alunos por computador na rede pública era de 71,2 alunos contra 49,7 na rede privada. Embora exista uma grande diferença, ambas ainda mostram o índice pouco utilizado do computador nas escolas do Brasil, se compararmos com países como Estados Unidos, Canadá ou Alemanha, ou com a média dos países da OCDE.

5 As perguntas pretende conhecer o acesso a computador na residência do aluno, o uso ou não por parte do aluno de algum software educativo e ao acesso à internet.

6 número de computadores disponíveis para alunos, professores, administração e tipo de conexão a internet

7 o Brasil não participou desse estudo opcional na última pesquisa. 
utilizam as TIC associadas a práticas tradicionais.

Assim, embora que alguns estudos mostrem que o uso das TIC não necessariamente melhora o rendimento educacional, seu uso e domínio são considerados indispensáveis para a inserção laboral e profissional dos futuros cidadãos. Por isso, para os países da OCDE a Internet e a Informática se tornam áreas de conhecimento indispensáveis para os jovens lidarem com as novas formas de produtividade.

Portanto, a questão não é se devemos usar ou não a tecnologia na educação, senão analisar como fazer melhor uso dela num mundo globalizado e diversificado para o desenvolvimento sócio-cognitivo de nossos alunos.

O objetivo do presente trabalho é apresentar elementos que ajudem a compreender o que a tecnologia possibilita em termos de desenvolvimento para nós como seres humanos e de que forma podemos estrutura e avaliar projetos de integração das TIC na sala de aula que promovam esse desenvolvimento.

\section{Tecnologia, paradigmas, conceitos e mitos}

A tecnologia como conceito é objeto de estudo por diferentes autores (BUNGE, 1980; MARX, 1980, LATOUR, 1987, LÈVY, 1993; entre outros) a partir de áreas de conhecimento diferenciadas decorrentes da sociologia, antropologia, filosofia, epistemologia, psicologia entre as mais representativas. Uma conceituação, portanto, deste termo torna-se desejável para explicitar de que ponto de análise estamos partindo quando analisamos tecnologias. Evidentemente, não é objetivo do presente artigo discorrer e debater esta problemática atual e relevante, mas sim partir de estudos anteriores que aportem os fundamentos necessários para a construção de nosso objeto de estudo, a saber: quais os aspectos são relevantes considerar na inserção da tecnologia no processo educativo.

Num sentido genérico o termo tecnologia refere-se ao uso e conhecimento de ferramentas, tecnicas, metodos e sistemas de 
organização ou de produção de objetos. Para Oliveira(2001,p.1010) "tecnologia refere-se a arranjos materiais e sociais que envolvem processos físicos e organizacionais, referidos ao conhecimento científico aplicável" Derivada do grego téchné (arte ou ofício) e logia (estudo de) é uma área de conhecimento humano que trata da invenção, produção e uso de ferramentas, artefatos e processos numa ação que tem por objetivo obter algum tipo de benefício individual ou grupal.

Filogeneticamente, a espécie humana tem registros que mostram que - uso e producao de tecnologia remete-se a tempos pré-históricos e alguns teóricos como Vygtosky (1998), Tomasello (2003), Leakey (1997) especulam que é justamente a nossa capacidade de inovação tecnológica o que facilitou nossa evolução em termos de espécie para tornar-nos a espécie dominante do planeta. Independente das abordagens antropológicas sobre a evolução da nossa espécie é evidente que a tecnologia sempre ocupou um lugar de destaque na construção da civilizacao (ELIAS, 1993) desde a invenção dos primeiros artefatos de caça à produção em massa de produtos industrializados, a tecnologia foi um elemento propulsor do desenvolvimento humano enquanto espécie.

Até relativamente pouco tempo atrás acreditava-se que unicamente os seres humanos desenvolviam tecnologia mas estudos recentes indicam que outros primatas e mamíferos superiores vivendo em comunidade também desenvolvem ferramentas e de alguma forma este conhecimento é passado para outros co-específicos(TOMASELLO, $2003)$.

O que parece ser o ponto comum de porque uma espécie desenvolve tecnologia é o fato de constituir um grupo social com interesses em comum (comunidade) e que utilizam algum mecanismo para transmissao de conhecimentos (educação). Este é o primeiro viés social presente na tecnologia, sua origem e necessidade.

Não há duvidas que a tecnologia afeta nossa sociedade (CASTELL, 2008; BUNGE 1980;1998) nos diversos sistemas sociais que compõem a civilização. De acordo com Bunge (1999) uma inovação técnica age 
sobre a sociedade direta ou indiretamente, mas a intensidade do impacto social dependem de vários outros fatores como originalidade, utilidade, custo, facilidade de uso (userfriendly), capacidade aquisitiva e nível educacional da população. As inovações tecnológicas podem alterar o modo de vida e por consequente a cultura de um sistema social. Por isso, toda inovação tecnológica é precedida de debates e expectativas, algumas das quais se concretizam e outras transformam-se apenas em mitos. Este é o segundo viés social presente na tecnologia, sua influência direta ou indireta em nossa cultura.

O debate filosófico sobre a relacao homem-tecnologia é amplo e antigo partindo do tecnicismo que ve a tecnologia como "a tábua de salvação da humanidade", apostando sempre nos aspectos benéficos da tecnologia. Esta visao é também compartilhada pelo Otimismo, que acredita no desenvolvimento tecnológico como moralmente bom. Para alguns críticos Karl Marx é o melhor exemplo de technooptimista. Num outro extremo do caleidoscopio filosófico encontrase o Pesimismo com suas diversas correntes (anarco-primitivismo, bioconservacionismo, ludismo e neo-ludismol os quais acreditam que as sociedades tecnológicas sao sociedades problemáticas e limitadas que afetam negativamente nossa saúde mental e tiram nossa liberdade. E finalmente o movimento denominado de Tecnologia Apropriada ou tecno-criticismo ou tecno-realismo que mais do que uma concepção sobre a tecnologia é uma proposição pró-ativa de inserção e desenvolvimento ecológica da tecnologia na sociedade. Nesse sentido, a Tecnologia Apropriada propõe produção de artefatos tecnológicos incorporando aspectos culturais, sociais e políticos da comunidade e propondo uma mudança no estilo de desenvolvimento com preocupação com as questões ambientais e com as fontes alternativas de energia (DAGNINO, BRANDÃO E NOVAES, $2004)$

No caso das Tecnologias da Informação e Comunicação (TIC) sua aparição e detaque ampliado a partir da metade do século anterior foi acompanhada de inúmeras discussões e debates, principalmente 
- que se refere ao mito principal que perpassa as TIC: sua inserção na sala de aula teria impactos diretos na aprendizagem e desenvolvimento do aluno. Este mito, supervalorizado até começo da década de 90 levou a um tecnicismo do processo educativo. Sua superação deu-se por uma visão na qual a tecnologia foi relativizada, vista como "um recurso a mais" no processo de ensino e de aprendizagem e que se instaura e vigora até o presente. Mas como veremos, também corre o risco de se "esvaziar" num mito de inserir "algo novo para nada mudar".

Nossa posição e que defenderemos ao longo do artigo é que as tecnologias longe de serem determinantes no processo educativo(tecnicismo) ou serem benéficas para todos os alunos (otimismo) ou ainda deshumanizarem o processo de ensino, tornando- contraproducente (ARMSTRONG, CASEMENT, 2001) têm um papel fundamental no desenvolvimento humano.

As tecnologias digitais ou comumente denominadas de tecnologias da informação e comunicação (TIC) sejam talvez as tecnologias modernas que mais apresentam explicitamente esta caracteristica sociabilidade, comunidade e educação. O motivo talvez que por serem ferramentas mentais (minds tool)agem mais sobre os proprios sujeitos que sobre objetos (JONASSEN, 1999).

Nesse sentido, tais ferramentas tornam-se signos nos sentido vygotskiano do termo(VYGOTSKY, 1988). Os signos, também chamados de Instrumentos psicológicos, são indispensáveis para a ação humana (educativa ou de outro tipo)(WERSCHT, 1999). Os signos permitem projetar-nos no tempo e no espaço, criar representações mentais simultâneas do mesmo fenômeno e compartilhar tudo isso socialmente. Esta capacidade dos signos deriva-se deles serem intersubjetivos, ou seja, socialmente compartilhados, incorporando as várias formas de interpretar intersubjetivamente o mundo que se acumularam numa cultura ao longo da sua história e perspectivos porque sua aprendizagem é feita sempre a partir da perspectiva do outro (TOMASELLO, 2003).

Assim, as tecnologias seriam signos na medida que permitem 
estruturar e organizar a ação humana; constituindo-se ao mesmo tempo, produtos e produtores da cultura numa dialética entre pessoas, sociedade, tecnologia e cultura que não pode ser simplificada ou reduzida a uma única questão, por exemplo, se devemos ou não inserir tecnologias na escola ou se sua inserção tem impacto no processo de aprendizagem humano.

Desta forma, acreditamos que o estudo da tecnologia não pode ser realizada de forma isolada da cultura e da sociedade e as tecnologias digitais não são excepção. Somos seres tecnológicos, usamos nosso conhecimento de forma a encontrar novas formas de produzir bens e serviços mais rápido e economicamente viável. Fazemos isso criando tecnologias que nos auxiliam nesse sentido. Por outro lado, as tecnologias permitem apropriar-nos de forma diferente dos conhecimentos, numa relação dinâmica entre conhecimento, sociedade e tecnologia. As tecnologias nos permitem, assim, visualizar, conhecer e experimentar fenômenos de formas diferentes apresentando o conhecimento desde perspectivas diferenciadas. O que, pela sua vez, se reflete na produção de novos conhecimentos que poderão levar à criação de outras tecnologias e assim sucessivamente num processo recursivo ascendente e fortemente dialético.

A nossa linguagem, é o maior exemplo de tecnologia, e permeia fortemente as TIC. A linguagem é o instrumento de comunicação mais amplamente difundido entre a espécie humana desde seu surgimento aproximadamente há uns 200.000 anos (linguagem oral) e tem nos transformado como espécie (LEAKEY, 1997). Seu aparecimento determinou o surgimento do Humano Moderno, "gente como nós [...] humanos com uma queda para a tecnologia e para a inovação, uma capacidade de expressão artística e um senso de moralidade" (LEAKEY, 1997, p.83). Posteriormente com o aparecimento da escrita fomos desenvolvendo outras possibilidades de tecnologias que contemplam a linguagem na sua esência como é o caso das TIC. Porém, sempre mantivemos a linguagem como nossa principal 
tecnologia, nosso artefato cultural mais precioso que permite a partir dele explorar os outros.

A linguagem é deste ponto de vista, o centro de nossa vida, de nosso desenvolvimento humano e desempenha duas funções, ser instrumento de comunicação e instrumento de pensamento. Com ela Com ela modulamos nosso pensamento, sem determiná-lo. Sem linguagem nosso pensamento ficaria imediato e dependente de estímulos diretos do ambiente, por meio da linguagem nos projetamos no tempo e no espaço num pensamento mediado que não precisa de estímulos diretos para acontecer. Podemos traçar hipótese, planejar ações, organizar pessoas tudo de forma mediata, sem a presença desses fatores "aqui e agora".

Essa funcionalidade da linguagem é transferida para as TIC por serem estas fortemente vinculadas à linguagem humana. Evidentemente que essa transferência não é uma mera cópia, há uma adaptação para as características presentes em cada TIC, como mail, fóruns, ferramentas de mensagens instantâneas, entre outras, cada uma com uma prática social instaurada a partir das particularidades simbiótica entre tecnologia-homem-objetivos. E este é o terceiro viés social da tecnologia, permite estruturar o pensamento e organizar pessoas de forma colaborativa.

Por isso, na medida em que fomos dominando e criando outras tecnologias, a partir da linguagem, nos tornamos seres mais complexos: socialmente mais complexos. Numa complexidade que tem uma base biológica, mas é essencialmente cultural (TOMASELLO, $2003)$.

Desta forma, a tecnologia, em particular as TIC, não nos tornam mais inteligentes, nos tornam seres mais complexos, pois permitem nossa comunicação, nossa ação e nossa representação de intenções. Possibilitam estabelecer convenções, estabelecer novas formas de relacionamentos, construir mundos, refletir sobre passado, presente e futuro e nos organizar para planejar o futuro. São estas tecnologias as TIC que chegaram nas salas de aula e 
criaram uma contexto sócio-cultural único no qual pessoas e tecnologias se engajam em ações pedagógicas.

\section{Entrelaçamentos da tecnologia com o processo educativo: emergência do social e do cognitivo no uso da tecnologia na educação}

Como já mencionamos, na atualidade poucos duvidam se a tecnologia deveria estar presente na educação, o que ainda fica pouco claro é como elas se entrelaçam no processo educativo. Apresentamos no item 1 algumas pesquisas que mostram benefícios do uso das TIC nas escolas e outras que não apresentam relação. E no item 2 apontamos para as diferentes dimensões do social que as tecnologias, em particular as TIC permite. Vamos dedicar este espaço para tentar compreender o entrelaçamento existente entre tecnologia e processo educativo.

Nossa premissa inicial é que as tecnologias nos permitem visualizar, conhecer e experimentar fenômenos de formas diferentes apresentando o conhecimento desde perspectivas diferenciadas, mas sempre com um viés social que permeia todo o processo. E que este processo torna-se recursivo quando novas tecnologias permitem produzir novos conhecimentos que levarão à criação de outras tecnologias e assim sucessivamente. Pois, a relação tecnologiaconhecimento-criação não é uma relação linear, mas dialética e interdependente (BUNGE, 1980).

Mas essa "não linearidade" é difícil de ser percebida numa concepção de mundo causa-efeito, por isso observamos que nas escolas, o uso das TICs é muitas vezes limitado, vistas como tecnologias "novas" seu uso limita-se à exploração e manuseio, ou seja, acredita-se que o próprio conhecimento delas seja suficiente para dar um "ganho qualitativo" numa relação direta de causaefeito. 
Nossa posição é divergente, consideramos que o uso relevante das TICs será aquele que as concebe como instrumentos de pensamento e de intersubjetividade e age para que as ações pedagógicas sejam complexas, intencionais e dialógicas, configurando o que Lèvy conceitua como tecnologia intelectual:

\begin{abstract}
a maioria dos programas atuais desempenham um papel de tecnologia intelectual: eles reorganizam, de uma forma ou de outra, a visão de mundo de seus usuários de modificam seus reflexos mentais. As redes informáticas modificam os circuitos de comunicação e de decisão das organizações. Na medida em que a informatização avança, certas funções são eliminadas, novas habilidades aparecem, a ecologia cognitiva se transforma [...] Cada nova inovação de informática abriu a possibilidade de novas relações entre homens e computadores [...] eles intervém sobre a comunicação, a percepção e as estratégias cognitivas de indivíduos e de grupos de trabalho (Lèvy, 1993, p. 54-56).
\end{abstract}

Usar as tecnologias como ferramentas do pensamento parte, portanto, de uma concepção de aprendizagem interacionista, na qual tanto aluno como professor, sujeitos ativos e aprendentes, entram em interação valendo-se de recursos e tecnologias para construir um espaço educativo que promova a aprendizagem ativa, construtiva, reflexiva, dialógica, intencional e contextualizada.

Desta forma o aluno aprende a reconhecer e resolver problemas, compreender novos fenômenos, construir modelos mentais e definir e regular seu próprio processo de aprendizagem em interação com outros e com as tecnologias, entre outros recursos (JONASSEN, 1999).

Mas esta concepção não necessariamente prevalente no espaço educativo, pois nos deparamos com que tradicionalmente as tecnologias têm sido utilizadas mais focadas no ensino, numa visão na qual o aluno aprende da tecnologia. O Aprender da Tecnologia tem como pressuposto que a tecnologia é detentora do conhecimento, e que este pode ser transmitido ao aprendiz como conhecimento externo ao sujeito e acabado, que pode ser "embutido" dentro da tecnologia e desta forma "aprendido" pelo aluno (Passerino, 2001). Em contraposição a esta visão, propomos um paradigma no qual as tecnologias são concebidas como ferramentas de pensamento (minds tool) e a aprendizagem surge a partir/com a tecnologia num 
processo interacionista e social superando a esfera puramente cognitiva individual (Passerino, 2001).

Desta forma, Aprender com Tecnologia, embasa-se em teorias interacionistas, nas quais o conhecimento é construído pelo sujeito em interação como parte de um processo ativo, engajado em atividades cognitivas inseridas num contexto social complexo.

\begin{abstract}
"... o aprendizado humano pressupõe uma natureza social específica e um processo através do qual as crianças penetram na vida intelectual daquelas que a cercam (p.115)... uma aspecto essencial do aprendizado é o fato de ele criar a zona de desenvolvimento proximal; ou seja, o aprendizado desperta vários processos internos de desenvolvimento, que são capazes de operar somente quando a criança interage com pessoas em seu ambiente e quando em cooperação com seus companheiros. Uma vez internalizados, esses processos tornam-se parte das aquisições do desenvolvimento independente da criança (VYGOTSKY, 1988, p.117-118).
\end{abstract}

A partir desta concepção, as TIC atuariam como instrumentos mediadores da aprendizagem, com três dimensões: a)como objetos de conhecimento: na medida que contém informações consideradas relevantes pelos sujeitos mais experientes para o ensino de um domínio, b) como instrumentos de pensamento: na medida que permitem elaborar crenças, testar hipótese, compreender fenômenos sociais, naturais, científicos ou culturais e desta forma elaborar representações mentais (modelos mentais)e c) como elementos de uma cultura: na medida que a partir das tecnologias é possível construir um espaço de negociação com os pares, participar de práticas culturais e desenvolver atitudes, modos de pensamentos, crenças e valores construídos a partir da interação com os outros por meio das tecnologias.

Desta forma, percebemos que estamos perante uma situaão diferenciada na qual a aprendizagem com tecnologia acrescenta um nível de abstração ao processo de aprendizagem humano porque se incorpora à ação como ferramenta de pensamento não individual e sim coletiva.

Defenemos que a inserção da tecnologia no processo educativo não pode partir de uma visão neutra da mesma, na qual insere-se como mais um recurso. Pelo contrário, é preciso um uso intencional da 
tecnologia promovendo seu potencial para a construção de ambientes aprendizagem mediados por tecnologias, essencialmente constituídos pelos sujeitos participantes, recursos tecnológicos e as ações metodológicas decorrentes no processo educativo (PASSERINO, 2001, 2005). Estes ambientes tornam-se interacionista na medida que a partir dos elementos básicos (sujeitos, recursos e metodologias) estruturamos o mesmo como "[...] um problema ou espaço de projeto (incluindo problema de contexto, problema de representação/simulação e problema de manipulação de espaço), casos relacionados, fontes de informação, ferramentas cognitivas, conversação, apoio contextual e social para as pessoas que participam" (JONASSEN, 1996, p. 80) .

Nesta concepção, os ambientes podem potencializar o desenvolvimento tanto social quanto cognitivo dos alunos se propiciarem que estes interpretem, e organizem o conhecimento pessoal, interajam e trabalhem em grupo na resolução de problemas, e fundamentalmente os ambientes propiciem a interação homem-mundo, levando o aluno à reflexão e à metacognição, ou seja, aprender a aprender.

Obviamente, que essa visão das tecnologias de comunicação e informação dentro de um espaço educativo requer uma propsota interdisciplinar do processo educacativo, quebrando com 0 currídulo disciplinar, e permitindo que a interdisciplinaridade interfira tanto na organização dos conteúdos como das ações possíveis, lembrando que

A organização dos conteúdos deve permitir o estudo de uma realidade que sempre é complexa e em cuja aprendizagem é preciso estabelecer o máximo de relações possíveis entre os diferentes conteúdos que são aprendidos para potencializar sua capacidade explicativa (ZABALA, 2002, p.35).

Apesar de acreditarmos que a tecnologia pode ser inserida no processo educativo com diferentes papeis e funções, também reconhecemos que existem limitações e condicionamentos que muitas 
vezes a própria tecnologia pode impor ao processo de ensino e aprendizagem em função de suas características, funcionalidades e das práticas culturais que enquanto grupo social desenvolvemos com elas. É esta a intencionalidade sócio-historicamente construída que permeia qualquer artefato criado pelo homem, e que portanto, potencialidades e limitações são importantes de serem explicitadas na hora de planejar e construir ambientes de aprendizagem mediados pelas tecnologias.

Lembrando que a construção de ambientes de aprendizagem é muito mais complexa do que inicialmente pode ser percebido. Existem diversas barreiras que afetam este processo. Entre os fatores que inibem o incremento da apropriação das TIC pelos professores encontram-se, segundo Balanskat, A.; Blamire (2007):

- Barreiras em nível de professor: Professores com poucas competências tecnológicas (sem letramento digital) e uma falta de confiança no uso das novas tecnologias no ensino são dois fatores determinantes para o nível de engajamento das TIC nas escolas. Esta barreira está diretamente relacionada com a qualidade da formação continuada dos professores.

- Barreiras em nível das escolas: Acesso limitado às TIC (seja por falta ou má organização de recursos ou de infraestrutura), problemas de manutenção e de qualidade de equipamentos (obsolescência), falta de softwares educacionais adequados. E principalmente ausência de uma dimensão nas estratégias pedagógicas nas escolas para a integração das tecnologias no processo educativo. Todos estes fatores são decisivos para os níveis de uso das TIC pelos professores.

- Barreiras em nível de sistema educacional: Em alguns países os sistemas educacionais encorajam uma estrutura rígida de disciplinas ou currículo que impede a integração das TIC na sala de aula. Isto pode ser evidenciado no Brasil 
especialmente no ensino médio que se volta para muitas vezes para um ensino enciclopédico com vistas ao vestibular.

Embora estes resultados apontados por Balanskat, A.; Blamire (2007) refiram-se à realidade européia, é possível identificar semelhanças na realidade brasileira, especialmente quando levamos em conta os estudos mais recentes disponíveis. Segundo o Censo Educacional do Ministério da Educação de 2006, existiam aproximadamente 659 mil computadores nas escolas do país ${ }^{8}$ (INEP, 2007), para atender 56,5 milhões de alunos nas diversas modalidades de ensino. Esta relação permite calcular o índice de 1,17 computador para cada 100 alunos. Se compararmos com países da Europa, por exemplo, a média em 2006 era de 11,4 computadores para cada 100 alunos9. Pelos dados da PNAD 2005, só 11,6\% dos alunos do Ensino Fundamental tiveram acesso à Internet nas escolas. Sendo que dos estudantes pobres que freqüentam o Ensino Fundamental, apenas 5,4\% utilizaram a Internet na escola enquanto que 37,7\% tiveram acesso quando se trata dos 10\% de estudantes mais ricos (WAISELFISZ, 2007a).

Se considerarmos apenas as escolas públicas o índice de acesso fica em aproximadamente 21,7 o dos alunos com 10 ou mais anos que usaram a internet na escola. Segundo o Censo Escolar de 2006, o país contava com 36.816 escolas públicas com laboratórios de informática (29.890 com conectividade) (WAISELFISZ, 2007a) e embora este número tenha aumentado em função das políticas públicas recentes desconhecemos quantas delas não os utilizam por falta de manutenção, problemas de infra-estrutura ou desconhecimento dos professores. Sem duvida, laboratórios centrais para atender toda a comunidade educativa tornam-se insuficientes para um uso realmente inovador das tecnologias, e barreiras precisam ser derrubadas para que mudanças aconteçam, sejam estas

\footnotetext{
8 Segundo o Censo Escolar de 2006, o país contava com 36.816 escolas públicas com laboratórios de informática (29.890 com conectividade) (Waiselfisz , 2007a)

9 Dados do European Commission. Benchmarking Access and Use of ICT in European Schools 2006
} 
barreiras em torno ao professor, em torno às escolas e em torno ao próprio sistema educacional como afirmavam Balanskat e Blamire (2007).

Mesmo a existência de laboratório e de formação continuada dos professores não garante um uso educativo das tecnologias em sala de aula como o proposto neste texto. Só será possível efetivar uma mudança na concepção do uso das TIC no processo educativo se for revisitado a concepção de processo educativo presente no imaginário escolar e sua mudança efetiva se dará na medida em que praticas culturais sejam alteradas.

Por isso, concordamos com Warschauer quando afirma que:

\begin{abstract}
"O uso do computador e da internet não gera beneficio automático fora das funções específicas. O uso da TIC é uma prática social que envolve acesso a artefatos físicos, conteúdos, habilidades e apoio social. A aquisição da TIC não é uma questão apenas de educação, mas também de poder. (2006, pg. 75)
\end{abstract}

Destacando que o desafio de um desenvolvimento sustentável e integral "não se encontra em superar a exclusão digital, mas em expandir o acesso e uso das TIC para promover a inclusão social" (WARSHAUER, 2006, p. 282) e compreender o papel das TIC no desenvolvimento humano e da sociedade com suas múltiplas dimensões e complexidade inerente, sem reduzir o processo ao um simples cálculo matemático.

Desta forma, acreditamos que futuras políticas publicas no âmbito das TIC na educação precisam passar por uma transformação tanto dos Parâmetros Curriculares Nacionais, quanto das Diretrizes de Cursos de Formação de Professores que devem contemplar a inserção de competências tecnológicas e de flexibilizando do currículo promovendo uma mudança cultural na qual as TIC sejam vistas como instrumentos de pensamento e de desenvolvimento individual e social. Enquanto isso não acontecer, acreditamos que as tecnologias continuarão sendo "novidades" na sala de aula em lugar de serem instrumentos e signos no desenvolvimento humano. 
Referencias

ARMSTRONG, A.; CASEMENT, C. A criança e a máquina: como os computadores colocam a educação de nossos filhos em risco. Porto Alegre: ArtMed, 2001.

BALANSKAT, A ;BLAMIRE, R. ICT in Schools: Trends, Innovations and Issues in 2006-2007. European Communities: European Schoolnet, 2007 Disponível em

http://insight.eun.org/shared/data/pdf/ict in schools 2006-

7 final.pdf

BUNGE, M. Ciência e Desenvolvimento. São Pualo: Ed. Universidade de São Paulo, 1980 .

BUNGE, M. Sociologia de La Ciência. Bs. As.: Editora Sudamericana, 1998 .

BUNGE, M. Sistemas Sociales y Filosofia. Bs. As.: Editora Sudamericana, 1999.

CAStelL, M. A Sociedade em Rede v.1. São Paulo: Editora Paz e Terra, 2008. Ed. 11

CGI. Pesquisa sobre o Uso das Tecnologias da Informação e da Comunicação no Brasil : TIC Domicílios e TIC Empresas 2008 [coordenação executiva e editorial/ executive and editorial coordination, Alexandre F. Barbosa ; tradução/ translation Karen Brito]. São Paulo : Comitê Gestor da Internet no Brasil, 2009.

DAGNINO,R.; BRANDÃO,F. ; NOVAES,H. Sobre o marco analítico- 
conceitual da tecnologia social. In: De Paulo A, Mello CJ, Nascimento Filho LPN, Koracakis T. Tecnologia social: uma estratégia para o desenvolvimento. Rio de Janeiro: Fundação Banco do Brasil; 2004 .

ELIAS, N. O PROCESSO CIVILIZADOR V. 2.: formação do estado e civilização. Rio de Janeiro, Editora Zahar, 1993.

INEP. Instituto Nacional de Estudos e Pesquisas Educacionais Anísio Teixeira. Educ@enso Sinopse Estatística da Educação Básica. Brasília, 2007

GALPERIN, H.; MARISCAL, J. DIGITAL POVERTY: Latin American and Caribbean Perspectives. REDIS-DIRSI, 2004.

GALPERIN, Brecha digital y desarrollo: mitos y realidades, RITLA, 2009 . Disponível

em

http://www.ritla.net/index.php?option=com content\&task=blogcategor $\underline{y \& i d=104 \& I \text { temid }=291}$

JONASSEN, D et alli. Learning with Technology: A Constructivist Perspective. New Jersey: Prentice Hall, 1999.

LATOUR, B., Science in Action, Cambridge, Harvard University Press, 1987 .

LEAKEY, H. A Origem da Espécie Humana.Rio de Janeiro: Rocco, 1997.

LEVY, P. Tecnologias da Inteligência: O futuro do pensamento na era da informática. Rio de Janeiro: Ed. 34, 1993.

MARX, K. - Capital y tecnología: manuscritos inéditos de 18611863. México, D. F.: Editorial Terra Nova, 1980. 
PISA. Programa Internacional de Avaliação de Alunos. PISA 2006 MARCO DE LA EVALUACIÓN Conocimientos y habilidades en Ciencias, Matemáticas y Lectura. OCDE. Organização para Cooperação e Desenvolvimento Econômico. Disponível em: http://www.pisa.oecd.org/dataoecd/59/2/39732471.pdf

OLIVEIRA, M.R.S. Do mito da tecnologia ao paradigma tecnológico; a mediação tecnológica nas práticas didático-pedagógicas. Revista Brasileira de Educação. Set/Out/Nov/Dez 2001 N 18 p.101-107

PASSERINO, L. Informática na Educação Infantil: perspectivas e possibilidades. In: Roman, E. D. e Steyer, V. (orgs). A criança de 0 a 6 anos e a educação infantil: um retrato multifacetado. Canoas: Ed. Ulbra, 2001, p.169 - 181.

PASSERINO, L. Ambientes Digitais Educacionais. Capítulo 3. In: PASSERINO, L., Pessoas com Autismo em Ambientes Digitais de Aprendizagem: estudos dos processos de interação e mediação. Tese de Doutorado em Informática na Educação. PGIE/UFRGS, 2005, 312p.

TOMASELLO, M. Origens Culturais da Aquisição do Conhecimento Humano. São Paulo: Marins Fontes, 2003 (Coleção Tópicos)

VYGotSKy, L. S Formação Social da Mente. $6^{\circ}$ Edição.- São Paulo: Martins Fontes, 1998.

WAISELFISZ, J. Mapa das desigualdades digitais no Brasil. Rede de Informação Tecnológica Latino-Americana, RITLA, 2007

WAISELFISZ, J. Lápis, borracha e teclado: tecnologia da informação na educação, Brasil e América Latina. Brasília: RITLA/MEC, $2007 a$. WARSCHAUER, M. Tecnologia e Inclusão Social.: a exclusão digital em debate. São Paulo, 2006. 
WERTSCH, J. La Mente en Acción. Buenos Aires: Aique, 1999.

ZABALA, A. Enfoque Globalizador e Pensamento Complexo: uma proposta para o currículo escolar. Porto Alegre: ArtMed, 2002 